\title{
EFFECT OF STARCH AS BINDER IN CARBON AEROGEL AND CARBON XEROGEL PREPARATION
}

Nicolás Rodríguez ${ }^{\mathrm{a}}$, Yazmin Yaneth Agámez-Pertuz ${ }^{\mathrm{a}}$, Eduard Romeroa, José de Jesús Díaz-Velásqueza, José Antonio Odriozola ${ }^{\mathrm{b}}$, Miguel Ángel Centeno ${ }^{\mathrm{b},{ }^{*}}$

${ }^{a}$ Departamento de Química, Facultad de Ciencias, Universidad Nacional de Colombia, AK 30 No 45-03, Bogotá, Colombia

${ }^{b}$ Instituto de Ciencia de Materiales de Sevilla, Centro Mixto Universidad de Sevilla-CSIC, Américo Vespucio 49, 41092, Sevilla, Spain

*centeno@icmse.csic.es

\section{Abstract}

Carbon aerogels and carbon xerogels were synthesized through resorcinol formaldehyde polycondensation using $\mathrm{Na}_{2} \mathrm{CO}_{3}$ as catalyst. The effect of soluble starch introduction in the organic gel preparation on the porous surface properties of these materials was studied. The role of the drying process of the organic gels on the changes in the surface and structural properties of these materials after the addition of soluble starch is discussed. The presence of starch in the prepared carbon xerogels results in the development of microporosity while maintaining the characteristic mesoporosity of carbon xerogels. The Brunauer - Emmett -Teller (BET) surface area increases from 309 $\mathrm{m}^{2} / \mathrm{g}$ in carbon xerogel without soluble starch until $685 \mathrm{~m}^{2} / \mathrm{g}$ when $10 \%$ of soluble starch is added. The R-value and average crystallite lattice parameters, inter-layer spacing, crystallite height, crystallite diameter and the average number of aromatic layers per carbon crystallite are discussed in function of drying step and presence of soluble starch. The surface properties were also studied by Raman and DRIFT spectroscopies.

Keywords: Carbon xerogel, carbon aerogel, starch, resorcinol-formaldehyde, Raman fitting. 


\section{Introduction}

Carbon aerogels (CA) and carbon xerogels (CX) are porous materials obtained by carbonizing organic polymer-based gels. The catalytic polymerization of resorcinol with formaldehyde in the presence of a solvent following Pekala's method is the most widely studied process for synthesizing these carbonaceous materials [1,2]. The difference between the procedure of obtaining of CA and CX lies in the drying step, where the excess of solvent is removed from hydrogel to obtain the organic gel. For CA, the solvent is removed by supercritical $\mathrm{CO}_{2}$ extraction, a method that keeps the microporous structure obtained in the gelation step. On removing the solvent by convective drying, the organic gel results in CX. In this later case the macro and mesoporous structure is preserved while microporosity often collapses. Resorcinol-formaldehyde polycondensation products are considered man-made polymers, but natural ones including cellulose, alginate, chitosan and starch show interesting features as raw materials to natural carbon materials because of their non-toxicity, low cost and availability [3-5]. Among those mentioned above, starch is an abundant, edible and wellknown polysaccharide found in the leaves, seeds and tuber of many vegetables. The versatility in starch processing makes it a promising binder and raw material to prepare stable matrices and microscopic granules with multiple uses [6-9]. Bakierska et. al. [10] using natural starches of different botanical origin synthesized microporous carbon aerogels with moderate surface areas and claim that tailored carbon materials might be developed depending on the drying and carbonization stages carried out. Meso- and microporous carbon aerogels with surface areas up to $1500 \mathrm{~m}^{2} \cdot \mathrm{g}^{-1}$ were reported by Chang et al. [3] on slightly modifying the solvent nature and the drying conditions of the hydrogels.

The porous structure of CA and CX materials may be controlled and tailored to fit specific applications on modifying the preparation conditions, which constitutes one of 
their main advantages. Many studies dealing with the effect of the different synthetic variables on the porous properties of the resulting $\mathrm{CA}$ and $\mathrm{CX}$ solids can be found in the literature. Changes in the concentration and nature of the reactants, particularly different hydroxylated benzene derivatives (phenol, cresol, catechol, tannic acid, etc.), aldehydes (furfural, benzaldehyde, etc.) and basic or acidic catalyst $\left(\mathrm{Na}_{2} \mathrm{CO}_{3}, \mathrm{NaOH}, \mathrm{HNO}_{3}, \mathrm{HClO}_{4}\right.$, etc.) strongly influence the characteristic of the synthesized solids. Furthermore, the use of additives in the carbon gel precursor solutions to control the gelation step and to prevent shrinkage during drying have been proposed, tailoring this way the surface properties of the final solid [11-15].

There is no evidence in the literature of the influence of polysaccharides in resorcinol-formaldehyde based $\mathrm{CA}$ or $\mathrm{CX}$ materials and considering the interesting properties that starch may generate in hydrogels and CA, a systematic investigation on the influence of using starch as additive to generate microporosity in $\mathrm{CX}$ as well as to obtain CX with similar properties to CA is presented in this work. Different starch concentrations were added in CA and CX preparations to analyze its effect in the porous structure and establish whether they can be used to tailor porous properties. The CA and CX obtained were characterized to determine their textural and structural properties, finding relationships among these properties, the drying step carried out and the presence of starch in the prepared carbonaceous materials.

\section{Experimental}

\subsection{Synthesis of the materials}

Two series of materials, carbon aerogels (CA) and carbon xerogels (CX) ones, were prepared through the polycondensation of resorcinol-formaldehyde water solutions but modifying the drying step. In both series the first synthesis step is the preparation of the resorcinol-formaldehyde hydrogel, according to the procedure described in [16]. To 
this procedure, consisting in the polycondensation of a 1:2 resorcinol:formaldehyde molar ratio mixture using sodium carbonate as catalyst, starch was added as binder.

Different starch amounts $(0.496,0.991$ and $1.487 \mathrm{~g})$ resorcinol $(9.910 \mathrm{~g}$ of resorcinol) and $\mathrm{Na}_{2} \mathrm{CO}_{3}$ as catalyst (resorcinol-to-catalyst molar ratio of 300 ) were added to $18.8 \mathrm{~mL}$ of water and the solution kept under continuous stirring. All solids were weighted in a digital electronic balance to a reliability of $0.0001 \mathrm{~g}$.

After $20 \mathrm{~min}$, the solution $\mathrm{pH}$ stabilizes $(\sim 6.7 \pm 0.1)$ and $13.5 \mathrm{~mL}$ of formaldehyde were added. The organic gel solution (OGS) were poured in a sealed cylindrical glass vial and kept for $24 \mathrm{~h}$ at room temperature and $120 \mathrm{~h}$ at $60^{\circ} \mathrm{C}$. The amount of starch used corresponds to 5,10 and $15 \mathrm{w} / \mathrm{w} \%$ of the amount of resorcinol employed. After the gelation step a dark red solid was obtained. This solid will be denominated from here as "organic gel".

The preparation of $\mathrm{CX}$ and CA materials differs in the drying step of the organic gel generated. In the case of the carbon xerogels, organic gels were directly pyrolyzed under $100 \mathrm{~mL} / \mathrm{min}$ of a nitrogen flow in a tubular furnace. The heating program included a first heating step from room temperature to $200{ }^{\circ} \mathrm{C}$ at a $5^{\circ} \mathrm{C} / \mathrm{min}$ rate, holding $30 \mathrm{~min}$ at $200^{\circ} \mathrm{C}$, and then increasing the temperature until $800^{\circ} \mathrm{C}$ at $10^{\circ} \mathrm{C} / \mathrm{min}$, maintaining this temperature for $3 \mathrm{~h}$.

For obtaining carbon aerogels, organic gels were first submitted to a controlled water-acetone exchange process. The organic gels were submerged in acetone at room temperature by 3 days, replacing the solvent each $12 \mathrm{~h}$. Next, the acetone was exchanged by $\mathrm{CO}_{2}$. For that purpose, in a Parr reactor, organic gels were immersed in liquid $\mathrm{CO}_{2}\left(900 \mathrm{psi}, 14^{\circ} \mathrm{C}\right)$ for a minimum of $4 \mathrm{~h}$ before flushing the system. Then, the system was refilled with $\mathrm{CO}_{2}$. This release/refill cycle was repeated four times. After this induction period, the solvent was extracted with supercritical $\mathrm{CO}_{2}$ conditions (1300 psi, $\left.45^{\circ} \mathrm{C}\right)$, above those of the binary critical curve of $\mathrm{CO}_{2}$ and acetone $\left(1100 \mathrm{psi}, 31^{\circ} \mathrm{C}\right)$. The organic gels were kept $12 \mathrm{~h}$ in supercritical conditions. Finally, the obtained materials were pyrolyzed under identical conditions than those of CX materials. 
The prepared samples were labelled as CX (for carbon xerogels) or CA (for carbon aerogels) followed by a number that indicates the weight concentration of starch used in the preparation of the organic gel $(5,10$ or $15 \%)$. For example, CX5 is a carbon xerogel with five percent of starch. Solids without starch in their preparation are denoted as $\mathrm{CXB}$ and $\mathrm{CAB}$.

\subsection{Characterization}

X-ray diffraction (XRD) spectra were recorded using a X'Pert Pro PANalytical instrument working with $\mathrm{Cu}-\mathrm{Ka}(40 \mathrm{~mA}, 45 \mathrm{kV})$ with $0.05^{\circ}$ step size and $300 \mathrm{~s}$ of step time, over a $2 \theta$ range from 10 to $80^{\circ}$. The average crystallite lattice parameters: inter-layer spacing $\left(d_{002}\right)$, crystallite height $\left(L_{c}\right)$, crystallite diameter $\left(L_{a}\right)$ and the average number of aromatic layers per carbon crystallite $\left(\mathrm{N}_{\mathrm{ave}}\right)$ are based from empirical Braggs and Scherrer equations (Eqs 1-4) $[17,18]$. The empirical $R$ value was defined according to several authors [17-20] as the graphical ratio of the (002) peak intensity relative to the background at the same scattering angle.

$$
\begin{aligned}
& d_{002}=\frac{\lambda}{2 \sin \theta_{002}} \\
& L_{c}=\frac{K_{c} \lambda}{\beta_{002} \cos \theta_{002}} \\
& L_{a}=\frac{K_{a} \lambda}{\beta_{100} \cos \theta_{100}} \\
& N_{\text {ave }}=\frac{L_{c}}{d_{002}}+1
\end{aligned}
$$

Where $\lambda$ is the wavelength of the incident X-ray, CuKa $1.5405 \AA ; \theta_{002}$ and $\theta_{100}$ are the peak position of (002) and (100) planes in degrees; $\beta_{002}$ and $\beta_{100}$ are the Full Width at Half Maximum (FWHM) of the corresponding diffraction peaks; $K_{c}$ is 0.89 and $\mathrm{K}_{\mathrm{a}} 1.84$ $[19,20]$. 
Raman spectra were recorded in a dispersive Horiva Jobin Yvon LabRam HR800 spectrometer, with a He-Ne green laser (532.14 nm) operating at $5 \mathrm{~mW}$ and a $50 \mathrm{x}$ objective. A confocal pinhole of $1000 \mu \mathrm{m}$ and a 600 lines $/ \mathrm{mm}$ grating was used. In such conditions, the diameter of the laser spot was $0,72 \mu \mathrm{m}$ and the spatial resolution of the measurements was $360 \mathrm{~nm}$. The spectra were obtained in the $100-4000 \mathrm{~cm}^{-1}$ Raman Shift range. In the first-order region (1000-1800 $\left.\mathrm{cm}^{-1}\right)$, Raman spectra were decomposed into several Lorentzian bands following the systematic procedure suggest by Kouketsu et. al. [18] for carbonaceous materials in metasediments, by using the "MagicPlot" fitting software. After a careful analysis of the shape of the Raman spectra of our samples following the criteria proposed by such authors, the first order spectra were decomposed in five Gaussian-Lorentzian (90:10) bands; D4, D1, D3, G and D2, with D4 and G positions fixed at 1245 and $1593 \mathrm{~cm}^{-1}$, respectively. The fitting parameters, including peak position, FWHM and intensity (integrated area), of every band were derived from the decomposition. A Levenberg-Marquardt algorithm was used to solve non-linear least squares problems and minimize the sum of squared residuals.

The goodness-of-fit is indicated by the $r^{2}$ values, where $r^{2}$ is defined by the following equation

$$
r^{2}=1-\frac{\sum_{i=1}^{n}\left(\hat{y}_{i}-y_{i}\right)^{2}}{\sum_{i=1}^{n}\left(y_{i}-\bar{y}\right)^{2}}
$$

Where $y_{i}$ is the measured intensity value, $\hat{y}_{i}$ is the intensity value calculated by peak fitting, and $\bar{y}$ is the mean of the measured intensity values. In all cases, $r^{2}$ values are in the 0.989 and 0.992 range. $A r^{2}$ value of 1 would be indicative of a perfect agreement between the measured spectrum and the calculated fit curve.

Diffuse reflectance infrared Fourier transform spectra (DRIFT) were recorded in a JASCO FT/IR - 6200 spectrometer, coupled to a PIKE accessory model EASI-DIFF. 
The spectra of pure samples were recorded in the $600-4000 \mathrm{~cm}^{-1}$ range, at $4 \mathrm{~cm}^{-1}$ resolution and after accumulation of 100 scans.

Textural properties were studied by nitrogen adsorption-desorption at liquid nitrogen temperature in a Micromeritics Tristar II instrument. Before the analysis, samples (200-300 mg) were degassed at $250^{\circ} \mathrm{C}$ for $12 \mathrm{~h}$ under vacuum. BET equation, t-plot and BJH method were used to calculate the specific area, the micropore area and the pore distribution, respectively. Adsorptive branch of the isotherm was used to determine the pore volume and pore diameters.

Scanning electron micrographs (SEM) were obtained with a scanning electron microscope HITACHI S-4800 FEG-fitted with secondary and electron backscattered detectors, operated at $5 \mathrm{kV}$.

\section{Results and discussion}

X-ray diffractograms of the samples are presented in figure 1a an 1b. All solids exhibit broad signals characteristics of amorphous coals at $25^{\circ}$ and $44^{\circ} 2 \theta$, ascribed to the (002) and (100) planes, respectively. The (002) peak is due to the ordering of aromatic rings and the (100) is attributed to the degree of aromatic ring condensation. The (002) peak is also attributed to the stacking of graphene sheets via Van der Waals forces [22, 23]. In general, carbon aerogels present more intense and well-defined diffractions than carbon xerogels pointing out to a higher crystalline character of these materials. As expected supercritical drying preserve the microporous structure of the polymer, and it may be assumed that the structural order can be maintained, at least partially, after pyrolysis. The low intensity of the diffraction lines of carbon xerogels suggests that the convective drying of the hydrogel results in a drastic evaporation of the solvent producing a collapse of the pore structure due to changes in surface tension of the solvent upon the formation of the vapor-liquid interphase [24]. This collapse results in a large shrinkage of the gel, generating in most polymers in a lower degree of order. 
A particular case seems to be the CX5 material, which, despite its xerogel nature, presents diffraction lines with intensities similar to those of the series of aerogel carbons. Thus, the addition of $5 \mathrm{w} / \mathrm{w} \%$ starch seems to allow maintaining the pore structure of the organic gel during the convective drying, avoiding that way the collapse of the structure. This result is the first evidence of the influence of the inclusion of the polysaccharide during the organic gel formulation in the characteristics of the carbon xerogels obtained.

A summary of the structural properties and the lattice parameters of the samples are presented in table $1 . \mathrm{CXB}$ and $\mathrm{CAB}$ have practically the same crystallite height (LC) and $\mathrm{N}_{\text {ave }}$ calculated values indicating that in absence of starch the drying step has no influence on the stacking of graphene layers. However, CAB presents a lower interlayer spacing (d002), higher crystallite diameter (La) and R value than CXB. The interlayer spacing value increase on decreasing the number of stacked graphitic layers organized in the carbonaceous structure. Thus, the increase of the crystallite diameter indicates an increase in material crystallinity, while the R-value is directly related to the concentration of single-graphene layers within a given sample, being the lowest R-values indicative of the highest concentration of single layers [20]. These results confirm that, in absence of starch, the drying step of the organic gels influences the structural properties of the obtained carbon. Thus, convective drying results in a decrease in the crystallinity of the material.

Although such influence of the drying step is maintained in the series of materials prepared with starch, the inclusion of this binder produces some changes in the lattice parameters of the carbons with respect to those of the materials without starch.

Lc values seems to decrease in the $C X$ samples and to increase in the CA ones. However, the observed differences are small and a trend relating them to the amount of starch incorporated is not evident. It seems that the presence of starch generates changes in graphene layer stacking, in a way that depends on the drying process carried out. 
The presence of starch also results in lower $\mathrm{La}$ and $\mathrm{R}$ values for the $\mathrm{CX}$ series of materials, while the opposite is true for the CA ones. These observations points to the influence of the starch concentration on the resorcinol-formaldehyde polycondensation process modifying the structure of the formed organic hydrogel. The structure of the modified hydrogel is a function of the drying method. The convective one generates, after pyrolysis, materials with a crystallinity lower than that obtained in those materials obtained after supercritical drying. It has been demonstrated that the presence of starch promotes the formation of methylene bridges with respect to free ortho and para aromatic groups during the condensation of phenol-formaldehyde mixtures [25]. The starch addition results in most exothermic curing reactions, therefore, the drying process affects the crosslinking extent of the resulting polymer due to the differences in the thermal profiles of the different drying processes. Condensation of polysaccharides with phenol at $\sim 250^{\circ} \mathrm{C}$ was early described, this process is accelerated by acid or base as well as by the presence of aldehydes [26]. The presence of starch in the RF hydrogel may interfere in the condensation reaction by increasing the crosslinking at temperatures above 170$180^{\circ} \mathrm{C}[25]$ by increasing the number of methylene bridges. The differences observed for $\mathrm{CX}$ and CA materials suggest that during convective drying polycondensation of both resorcinol-formaldehyde and resorcinol-starch occurs resulting in disordered materials with smaller crystallite sizes. On the contrary, the supercritical drying condition favors the resorcinol-formaldehyde condensation, that occurs at lower temperatures than the resorcinol-starch condensation, facilitating the crystallite growth.

Interestingly, although the introduction of a large concentration of starch (15\%) results in carbon xerogels with a lower R-value, characteristics of a lower number of single graphene layers, which should indicate a material of lower crystallinity, the introduction of just $5 \%$ starch results in R-values similar to that of the CXB material, suggests that the degree of crystallinity is similar for both samples, as can be seen in the XRD patterns (figure 1). 
To characterize the crystallinity degree of carbonaceous materials Raman spectroscopy is an appropriate and relevant technique commonly used [21, 27, 28]. Raman spectra of carbons are commonly divided into first-order $\left(1000-1800 \mathrm{~cm}^{-1}\right)$ and second-order regions $\left(2500-3400 \mathrm{~cm}^{-1}\right)$. In the first-order region, the vibrational modes of crystalline graphite (G-bands) and D-bands associated to the presence of crystal defects and disordered structures are observed [29]. A single band at about $1580 \mathrm{~cm}^{-1}$ ( $G$ band) is observed for perfect graphite, this band is ascribed to the stretching mode, $E_{2 g}$ symmetry, of aromatic layers of crystalline graphite [30, 31]. On increasing disorder, additional bands appear as a result of defects in the microcrystalline lattice [21]. Although the denomination, number and interpretation of these bands are still controversial, up to four D bands have been proposed [29,32]: The $1350 \mathrm{~cm}^{-1}$ band, called D1, corresponds to a graphitic lattice vibration mode with $A_{1 g}$ symmetry and is ascribed to imperfections such as defects and heteroatoms $[31,33]$. The $D 2\left(1620 \mathrm{~cm}^{-1}\right)$ band is always present if D1 appears and their relative intensity (in this work, the signal intensity is measured through the area under the curve) decreases on increasing the organization degree. This band is ascribed to the stretching mode of the aromatic layers, as for the $G$ band, but involving graphene layers which are not directly inserted between two other graphene layers [34]. The $1510 \mathrm{~cm}^{-1}$ band (D3 band) usually appearing as a very broad band around $1500-1550 \mathrm{~cm}^{-1}$ has been suggested to originate from amorphous $\mathrm{sp}^{2}$-bonded forms of carbon, such as organic molecules, fragments or functional groups. Some authors also suggest that this band accounts for the reacting sites and consequently the char reactivity [35]. The $1245 \mathrm{~cm}^{-1}$ band (D4 band) appears usually in very poorly organized materials, such as soot and coal chars [36-38]. Dippel et. al. attributed it to $\mathrm{sp}^{3}-\mathrm{sp}^{2}$ mixed sites at the periphery of crystallites or to $\mathrm{C}-\mathrm{C}$ and $\mathrm{C}=\mathrm{C}$ stretching vibrations of polyene-like structures [39].

In the second order region four bands are generally observed at about 2490 , 2700,2930 and $3240 \mathrm{~cm}^{-1}$, due to overtones and combination bands of the first order region. The first overtone of the $\mathrm{D} 1$ band $\left(2^{*} \mathrm{D} 1\right)$ at $\sim 2700 \mathrm{~cm}^{-1}$ usually is the one with the 
highest intensity) $[33,40]$. The band at $\sim 2930 \mathrm{~cm}^{-1}$ is a combination of the G and D1 modes characteristic for disturbed graphitic structures $(\mathrm{G}+\mathrm{D} 1)$. The $\sim 3240 \mathrm{~cm}^{-1}$ band is assigned to the first overtone of the D2 band [33], and the $\sim 2490 \mathrm{~cm}^{-1}$ band is ascribed to the Raman active first overtone of a Raman inactive graphitic lattice vibration mode at $1245 \mathrm{~cm}^{-1}\left(2^{*} \mathrm{D} 4\right)$. These last two bands appear as shoulders of $\left(2^{*} \mathrm{D} 1\right)$ and $(\mathrm{G}+\mathrm{D} 1)$ bands.

Representative Raman spectra of the prepared carbon materials are presented in figure 2. In all materials, the typical Raman bands of disordered carbonaceous materials, characteristics of medium-grade ones, are observed [21]. However, differences in the crystallinity between both series of carbons are clear, as evidenced by their different G/D1 intensity ratio ( 1,25 for xerogels and $\sim 0,95$ for aerogels). In order to gain insights about the influence of the drying step and the addition of starch as binder in the crystallinity of the final material obtained, a decomposition of the first order Raman spectra in five bands (D4, D1, D3, G and D2) was carried out. In the fitting procedure, D4 and G positions were fixed at 1245 and $1593 \mathrm{~cm}^{-1}$, respectively. This methodology was selected according to Kouketsu et al. [21] and because of the G/D1 ratio is in all cases $<1,5$. A graphical example of the deconvolution results for each series of carbons is presented in figure 3 , and all fitting parameters are shown in table 2

The poorly organized carbonaceous nature is indicated by the occurrence of the D3 and D4 bands, and the overlapping of D2 and G bands. The FWHM of the G band is a frequently used measure of structural order of carbonaceous materials and a decreasing value indicates an improvement in order [41]. Figure 3 qualitatively shows that $\mathrm{G}$ band contribution in CA15 is higher than in CX15 and its FWHM is lower $\left(51 \mathrm{~cm}^{-}\right.$ ${ }^{1}$ against $78 \mathrm{~cm}^{-1}$ respectively). All G band FWHM values (see table 2) are lower than those obtained by Bar-Ziv et al. [36] in petroleum cokes, indicating a greater degree of organization in the materials of this study, although the cokes reported in [36] were treated at a higher temperature $\left(1000^{\circ} \mathrm{C}\right)$. CX15 has the highest $\mathrm{G}$ band FWHM being the studied material with less organized aromatic layers, in good agreement with the 
$X R D$ results shown above. Several studies reported that the decreasing in the FWHM of the $\mathrm{G}$ and $\mathrm{D} 1$ bands indicates an increasing degree of graphitization of the carbonaceous material $[33,40,42]$. Accordingly, in table 2 it is observed that FWHM values of all aerogels samples are lower than those of the xerogels ones, evidencing the more organized character of the CA materials in comparison with the CX ones. These results can be is explained by the advantages of the supercritical drying against convective drying.

With respect to the influence of the starch addition, in CX materials an increment of the FWHM of D4, D1, G and D2 bands, is observed, pointing out to a decrease in the order degree of the solids with the starch concentration, being the CX15 the material the one with a lower number of graphitic layers, in agreement with XRD results (table 1 ).

For the carbon aerogels series, CA, the presence of starch results in higher FWHM values than that of $\mathrm{CAB}$ (the solid without starch), which again points to a decrease in the order degree of the carbon after starch addition. However, the lowest order degree (highest FWHM value) is evidenced in the CA5 solid, increasing afterwards with the concentration of added starch. This information is interesting since the observed lattice parameters values by XRD of the CA series (table 1) did not allow to observe any clear difference. From here, the influence of the starch as additive in the control of the crystallinity of the carbonaceous materials is evidenced. In previous works, starch had been employed to create carbon aerogels without using resorcinol-formaldehyde polymerization reaction, but exploiting the supercritical drying to keep the microporous structure $[43,44]$.

The textural properties of all materials were also studied, see table 3. In figure 4, isotherms of solids are showed. All samples present type IV characteristic isotherms according to the IUPAC classification, indicating that they are mesoporous materials wherein it is produced the adsorption in a multilayer way, which is observed in an ascendant central zone due to the adsorption of more layers on the material surface. It is also observed a good contribution of microporosity at relatively low pressures, 
characteristic of activated carbonaceous materials. In general, the isotherms form is very similar, indicating that the two methodologies employed to prepare CX and CA solids are responsible for the porosity. The isotherms exhibit type $\mathrm{H} 4$ hysteresis, characteristic of carbonaceous materials with laminar particles and flexible porous with slit-type morphology.

BET surface areas of xerogels (CX) are in the $309-685 \mathrm{~m}^{2} / \mathrm{g}$ range and those of aerogels (CA) in the $522-615 \mathrm{~m}^{2} / \mathrm{g}$ one. For comparative purposes, in table 4 the characteristics of some carbon xerogels and aerogels from literature are compiled. The BET area of the xerogel without starch, CXB, is $309 \mathrm{~m}^{2} / \mathrm{g}$, close to that reported in literature for carbons prepared by a similar synthesis methodology [16]. After starch addition, the external area of the xerogels increases up to $100 \mathrm{~m}^{2} / \mathrm{g}$, but the increase of the micropore area is the most important change. In fact, the micropore volume increases at least 5 times with respect to that of $\mathrm{CXB}$. CX is characterized by has a strong contribution of mesopores and a low one of micropores, meanwhile in CX5, CX10, and CX15 materials the micropore contribution arrives to 40 percent. According to the carbon aerogels obtained from starch by Bakierska, et. al. [10], microporosity in CX5, CX10 and CX15 samples is mainly due to the polymeric structure formed by the starch during the gelation step which remains after the pyrolysis. The micropore volume of these three samples is similar in all cases, while that of the carbon without starch, $C X B$, it has the typical value of a carbon xerogel with collapsed structure [45].

CA series have similar pore volume and micropore area increases slightly with respect to $\mathrm{CAB}$ if concentration of starch increases. CA5, CA10 and CA15 have higher micropore area than CAB. The supercritical drying keeps micropore structure generated by resorcinol-formaldehyde polymerization and also keeps the micropore structure formed in gelation step of starch. BJH pore diameters in CX and CA series are characteristic of mesoporous materials, being CXB the material with the highest pore diameter, and CA series with pores near to micropore range. CX5 is the material with higher percentage of microporosity and less pore diameter. In DRX analysis was 
observed that CX5 presented characteristics similar to CA series. The FWHM of D3 in Raman peak fitting also presents a value within the range of the values obtained for CA series; as mentioned earlier, this band corresponds to amorphous $\mathrm{sp}^{2}$-bonded forms of carbon as resorcinol formaldehyde polymerization residues and starch residues after carbonization.

Representative SEM micrographs of selected samples are shown in figure 5. All samples are composed of aggregates of grains. The agglomeration is more evident in the carbon xerogels, evidencing the influence of the drying method in the textural properties. Convective drying is a more drastic process than supercritical $\mathrm{CO}_{2}$ one, resulting in a higher carbon particles agglomeration. Whatever the drying procedure carried out, carbons produced with starch addition present a lower agglomeration degree than raw carbons $(\mathrm{CAB}$ and $\mathrm{CXB})$. It is observed that after the carbonization a globular or granular structure has been maintained with a three-dimensional network formed during the polymerization which is in agreement with the textural results where the materials have micro and mesoporosity.

It is well known that DRIFTS spectroscopy provides information about the surface chemical structure of carbon materials [46-48]. The DRIFTS spectra of all prepared carbons are presented in figure 6. Irrespectively of the drying method (convective or supercritical $\mathrm{CO}_{2}$ extraction), the carbonaceous materials prepared without starch (CXB and $\mathrm{CAB}$ ) present similar spectra, showing small and very few intense IR bands, indicating a very low activation degree of the surface. In fact, the main visible bands are due to aromatic and aliphatic hydrocarbons; $\mathrm{C}=\mathrm{C}$ stretching vibration, $1620 \mathrm{~cm}^{-1}, \mathrm{C}-\mathrm{C}$ stretching vibrations, $1450 \mathrm{~cm}^{-1}$, and $\mathrm{C}-\mathrm{H}$ out of plane vibrations of substituted benzene rings $\left(660,824\right.$ and $\left.910 \mathrm{~cm}^{-1}\right)$ [49]. However, the materials prepared after starch addition present more intense DRIFTS signals, as well as new bands ascribed to different surface species. This evidences that the starch addition favors the surface functionalization 
during the pyrolysis procedure, which is a very interesting result faced to the use of the material in future applications, mainly in catalysis, where the surface properties of the carbon plays a decisive role [50]. The surface functionalization of the starch-added produced carbon strongly depends on the drying procedure carried out. In the case of the supercritical $\mathrm{CO}_{2}$ extraction (figure $6 \mathrm{~b}$ ), although the intensity of the DRIFTS bands is not change to a great extension, new bands are clearly detected at 2950, 2920 and $2877 \mathrm{~cm}^{-1}$, characteristics of aliphatic $\mathrm{C}-\mathrm{H}$ stretching, and one at $1730 \mathrm{~cm}^{-1}$, due to $\mathrm{C}=\mathrm{O}$ groups $[47,48,51]$. The intensity of such bands increases with the content of the starch, which reinforces the assumption of the positive influence of starch in the surface functionalization. In order to clearly visualize the type of surface species formed, in figure $6 c$ it is shown the difference DRIFTS spectra of the materials with $15 \%$ starch addition and that without starch. A much intense surface functionalization is obtained when a convective drying is carried out, figure 5 a, especially when the amount of starch is $10 \%$ weight or higher. This must be related with the presence of an oxidant atmosphere during the drying. In good agreement with this, together with the surface DRIFTS bands of $\mathrm{C}=\mathrm{O}$ and aliphatic $\mathrm{C}-\mathrm{H}$ species observed and described above for the carbon aerogels, new bands at 3541, 3398, 3310, 3055, 1910, 1590 and $1186 \mathrm{~cm}^{-1}$, among others, emerged for the xerogels. The one at 3541 is characteristic of phenol $\mathrm{O}-\mathrm{H}$ groups of oxidized carbons [47], which, together with the wide and broad band in the in the $3600-3200 \mathrm{~cm}^{-}$ 1 region, due to hydrogen-bridged $\mathrm{OH}$ stretching of adsorbed water, support the existence of a carbon oxidized surface. In this sense, the band detected at $1910 \mathrm{~cm}^{-1}$ could be ascribed to cyclic anhydride or lactone groups [47], and those in the 1030-1300 $\mathrm{cm}^{-1}$ region to C-O single bonds from several functional groups, such as esters (1150$\left.1250 \mathrm{~cm}^{-1}\right)$, acidic and cyclic anhydrides $\left(1180-1300 \mathrm{~cm}^{-1}\right)$, lactones $\left(1160-1370 \mathrm{~cm}^{-1}\right)$, ethers $\left(1120-1300 \mathrm{~cm}^{-1}\right)$, cyclic ethers $\left(1140 \mathrm{~cm}^{-1}\right)$, phenolic groups $\left(1180-1220 \mathrm{~cm}^{-1}\right)$, epoxides $\left(1220 \mathrm{~cm}^{-1}\right)$, carboxyl-carbonates, primary alcohols, etc. all of them reported in porous carbon materials $[47,52-54]$. Besides this, the band at $3055 \mathrm{~cm}^{-1}$ demonstrated the formation of new aromatic rings, since it is due to aromatic $\mathrm{C}-\mathrm{H}$ groups [47]. The 
presence of phenol groups, oxidized carbon species and adsorbed water on the surface of the carbon must increase the hydrophilicity of the surface, as well as its acidity, which for sure must improve the surface reactivity of the material.

\section{Conclusions}

Carbon xerogels with similar structural properties to carbon aerogels were synthesized due to starch inclusion during the organic polymer preparation, allowing in this way to tailor the surface and textural properties of the carbonaceous material obtained. Addition of starch allows obtaining carbon materials by convective drying with similar textural properties than those obtain by supercritical drying step, thus reducing time and costs in the process. Carbon aerogels obtained are in general more organized materials than xerogels, but the inclusion of a $5 \% \mathrm{w} / \mathrm{w}$ of starch significantly favors the formation of aromatic layers and a defined structure with very similar characteristics to the carbonaceous materials prepared by supercritical drying. The addition of starch disfavors the formation of carbon layers in carbon xerogels but favors the crystallite size growth in the aerogels materials. At surface level, starch generate micropore structure which usually collapses in convective drying. The addition of starch allows to generate microporosity in the surface of $\mathrm{CX}$ an $\mathrm{CA}$, being more evident its contribution in the materials obtained by convective drying.

Finally, starch presence improved the surface functionalization of the obtain carbonaceous materials, especially after convective drying, facilitating the formation of a large variety and quantity of surface oxidized species, able to adsorb atmospheric water. These results highlight starch as an additive that modifies in a controlled manner the surface and structural properties of based resorcinol-formaldehyde CX and CA, and contribute to the tailoring and preparation of man-made carbonaceous carbon materials.

\section{Acknowledgments}


Financial support for this work has been obtained from the Spanish Ministerio de Educación y Competitividad (MINECO) projects ENE2013-47880-C3-2-R and ENE201782451-C3-3-R), co-financed by FEDER funds from the European Union. Nicolás Rodríguez thanks COLCIENCIAS for financial support through national doctoral scholarship No.617/2013.

\section{References}

[1] R.W. Pekala, Organic aerogels from the polycondensation of resorcinol with formaldehyde, J. Mater. Sci., 24 (1989) 3221-3227.

[2] R.W. Pekala, J.C. Farmer, C.T. Alviso, T.D. Tran, S.T. Mayer, J.M. Miller, B. Dunn, Carbon aerogels for electrochemical applications, J. Non-Cryst Solids 225 (1998) 74-80

[3] X. Chang, D. Chen, X. Jiao, Starch-derived carbon aerogels with highperformance for sorption of cationic dyes, Polymer, 51 (2010) 3801-3807.

[4] C. Xu, X. Luo, X. Lin, X. Zhuo, L. Liang, Preparation and characterization of polylactide/thermoplastic konjac glucomannan blends, Polymer, 50 (2009) 36983705.

[5] Z. Feng, Z. Shao, J. Yao, Y. Huang, X. Chen, Protein adsorption and separation with chitosan-based amphoteric membranes, Polymer, 50 (2009) 1257-1263.

[6] A. Varzi, S. Passerini, Enabling high areal capacitance in electrochemical double layer capacitors by means of the environmentally friendly starch binder, Journal of Power Sources, 300 (2015) 216-222.

[7] K. Drobíková, D. Plachá, O. Motyka, R. Gabor, K.M. Kutláková, S. Vallová, J. Seidlerová, Recycling of blast furnace sludge by briquetting with starch binder: Waste gas from thermal treatment utilizable as a fuel, Waste Management, 48 (2016) 471-477.

[8] E.I. Nep, K. Asare-Addo, M.U. Ghori, B.R. Conway, A.M. Smith, Starch-free grewia gum matrices: Compaction, swelling, erosion and drug release behaviour, International Journal of Pharmaceutics, 496 (2015) 689-698.

[9] S. Somboonchan, S. Lubbers, G. Roudaut, Water and temperature contribution to the structuration of starch matrices in the presence of flavour, Food Chemistry, 195 (2016) 79-86.

[10] M. Bakierska, M. Molenda, D. Majda, R. Dziembaj, Functional Starch Based Carbon Aerogels for Energy Applications, Procedia Engineering, 98 (2014) 14-19. [11] M. Haghgoo, A.A. Yousefi, M.J. Zohuriaan Mehr, Nano porous structure of resorcinol-formaldehyde xerogels and aerogels: effect of sodium dodecylbenzene sulfonate, Iranian Polymer Journal, 21 (2012) 211-219.

[12] K.T. Lee, S.M. Oh, Novel synthesis of porous carbons with tunable pore size by surfactant-templated sol-gel process and carbonisation, Chemical Communications, (2002) 2722-2723.

[13] N. Vera-Hincapié, E. Romero-Malagón, F. Carrasco-Marín, Y. Agámez-Pertuz, J. Díaz-Velásquez, Effect of the addition of a second phenol on the textural properties of carbon aerogels, Adsorption, 22 (2016) 81-87. 
[14] S. Wang, Y. Xu, Meifang Yan, L. Zhang, Z. Liu, The effect of surfactants on carbon xerogel structure and CO2 capture, J. Non-Cryst Solids 499 (2018) 101106

[15] I.D. Alonso-Buenaposada, N. Rey-Raap, E.G. Calvo, J.A. Menéndez, A. Arenillas, Effect of methanol content in commercial formaldehyde solutions on the porosity of RF carbon xerogels, J. Non-Cryst Solids 426 (2015) 13-18

[16] N. Job, F. Sabatier, J.-P. Pirard, M. Crine, A. Léonard, Towards the production of carbon xerogel monoliths by optimizing convective drying conditions, Carbon, 44 (2006) 2534-2542.

[17] Y. Liu, J.S. Xue, T. Zheng, J.R. Dahn, Mechanism of lithium insertion in hard carbons prepared by pyrolysis of epoxy resins, Carbon, 34 (1996) 193-200.

[18] D. Qu, Investigation of oxygen reduction on activated carbon electrodes in alkaline solution, Carbon, 45 (2007) 1296-1301.

[19] G.N. Okolo, H.W.J.P. Neomagus, R.C. Everson, M.J. Roberts, J.R. Bunt, R. Sakurovs, J.P. Mathews, Chemical-structural properties of South African bituminous coals: Insights from wide angle XRD-carbon fraction analysis, ATRFTIR, solid state 13C NMR, and HRTEM techniques, Fuel, 158 (2015) 779-792.

[20] J. Collins, D. Zheng, T. Ngo, D. Qu, M. Foster, Partial graphitization of activated carbon by surface acidification, Carbon, 79 (2014) 500-517.

[21] Y. Kouketsu, T. Mizukami, H. Mori, S. Endo, M. Aoya, H. Hara, D. Nakamura, S. Wallis, A new approach to develop the Raman carbonaceous material geothermometer for low-grade metamorphism using peak width, Island Arc, 23 (2014) 33-50.

[22] V. Likodimos, T.A. Steriotis, S.K. Papageorgiou, G.E. Romanos, R.R.N. Marques, R.P. Rocha, J.L. Faria, M.F.R. Pereira, J.L. Figueiredo, A.M.T. Silva, P. Falaras, Controlled surface functionalization of multiwall carbon nanotubes by HNO3 hydrothermal oxidation, Carbon, 69 (2014) 311-326.

[23] Z.Q. Li, C.J. Lu, Z.P. Xia, Y. Zhou, Z. Luo, X-ray diffraction patterns of graphite and turbostratic carbon, Carbon, 45 (2007) 1686-1695.

[24] C. Moreno-Castilla, F.J. Maldonado-Hódar, Carbon aerogels for catalysis applications: An overview, Carbon, 43 (2005) 455-465.

[25] M.Turunen, L. Alvila, T.T. Pakkanen, J. Rainio, Modification of PhenolFormaldehyde Resol Resins by Lignin, Starch, and Urea, Journal of Applied Polymer Science, 88 (2003) 582-588.

[26] E.E. Novotny, C.J. Romieux, Condensation product of phenol and starches, US Patent 1815930 (1931).

[27] S. Goler, A. Hagadorn, D.M. Ratzan, R. Bagnall, A. Cacciola, J. McInerney, J.T. Yardley, Using Raman spectroscopy to estimate the dates of carbon-based inks from Ancient Egypt, Journal of Cultural Heritage, (2018).

[28] H. Ge, Z. Ye, R. He, Raman spectroscopy of diesel and gasoline engine-out soot using different laser power, Journal of Environmental Sciences, (2018).

[29] S. Takabayashi, R. Ješko, M. Shinohara, H. Hayashi, R. Sugimoto, S. Ogawa, Y. Takakuwa, Chemical structural analysis of diamondlike carbon films: II. Raman analysis, Surface Science, 668 (2018) 36-41.

[30] J.J. Song, D.D.L. Chung, P.C. Eklund, M.S. Dresselhaus, Raman scattering in graphite intercalation compounds, Solid State Communications, 20 (1976) 1111-1115. 
[31] A.C. Ferrari, J. Robertson, Interpretation of Raman spectra of disordered and amorphous carbon, Physical Review B, 61 (2000) 14095-14107.

[32] K. Gao, Y. Wang, X. Wei, L. Qiang, B. Zhang, J. Zhang, Hydrogenated amorphous carbon films with different nanostructure: A comparative study, Chemical Physics Letters, 715 (2019) 330-334.

[33] Y. Wang, D.C. Alsmeyer, R.L. McCreery, Raman spectroscopy of carbon materials: structural basis of observed spectra, Chemistry of Materials, 2 (1990) 557-563.

[34] G. Katagiri, H. Ishida, A. Ishitani, Raman spectra of graphite edge planes, Carbon, 26 (1988) 565-571.

[35] Y. Yu, M. Xu, H. Yao, D. Yu, Y. Qiao, J. Sui, X. Liu, Q. Cao, Char characteristics and particulate matter formation during Chinese bituminous coal combustion, Proceedings of the Combustion Institute, 31 (2007) 1947-1954.

[36] E. Bar-Ziv, A. Zaida, P. Salatino, O. Senneca, Diagnostics of carbon gasification by raman microprobe spectroscopy, Proceedings of the Combustion Institute, 28 (2000) 2369-2374.

[37] A. Zaida, E. Bar-Ziv, L.R. Radovic, Y.-J. Lee, Further development of Raman Microprobe spectroscopy for characterization of char reactivity, Proceedings of the Combustion Institute, 31 (2007) 1881-1887.

[38] T. Livneh, E. Bar-Ziv, O. Senneca, P. Salatino, Evolution of Reactivity of Highly Porous Chars from Raman Microscopy, Combustion Science and Technology, 153 (2000) 65-82.

[39] B. Dippel, J. Heintzenberg, Soot characterization in atmospheric particles from different sources by NIR FT Raman spectroscopy, Journal of Aerosol Science, 30 (1999) 907-908.

[40] A. Cuesta, P. Dhamelincourt, J. Laureyns, A. Martínez-Alonso, J.M.D. Tascón, Raman microprobe studies on carbon materials, Carbon, 32 (1994) 1523-1532.

[41] O. Beyssac, B. Goffe, J.P. Petitet, E. Froigneux, M. Moreau, J.N. Rouzaud, On the characterization of disordered and heterogeneous carbonaceous materials by Raman spectroscopy, Spectrochimica acta. Part A, Molecular and biomolecular spectroscopy, 59 (2003) 2267-2276.

[42] T. Gruber, T.W. Zerda, M. Gerspacher, Raman studies of heat-treated carbon blacks, Carbon, 32 (1994) 1377-1382.

[43] M. Enterría, F.J. Martín-Jimeno, F. Suárez-García, J.I. Paredes, M.F.R. Pereira, J.I. Martins, A. Martínez-Alonso, J.M.D. Tascón, J.L. Figueiredo, Effect of nanostructure on the supercapacitor performance of activated carbon xerogels obtained from hydrothermally carbonized glucose-graphene oxide hybrids, Carbon, 105 (2016) 474-483.

[44] L. Bao, X. Zhu, H. Dai, Y. Tao, X. Zhou, W. Liu, Y. Kong, Synthesis of porous starch xerogels modified with mercaptosuccinic acid to remove hazardous gardenia yellow, International Journal of Biological Macromolecules, 89 (2016) 389-395.

[45] E. Bailón-García, F. Carrasco-Marín, A.F. Pérez-Cadenas, F.J. MaldonadoHódar, Development of carbon xerogels as alternative Pt-supports for the selective hydrogenation of citral, Catalysis Communications, 58 (2015) 64-69.

[46] J. Wang, B. Shen, D. Kang, P. Yuan, C. Wu, Investigate the interactions between biomass components during pyrolysis using in-situ DRIFTS and TGA, Chemical Engineering Science, 195 (2019) 767-776. 
[47] P.E. Fanning, M.A. Vannice, A DRIFTS study of the formation of surface groups on carbon by oxidation, Carbon, 31 (1993) 721-730.

[48] B.J. Meldrum, C.H. Rochester, Infrared spectra of carbonaceous chars under carbonization and oxidation conditions, Fuel, 70 (1991) 57-63.

[49] D. Lin-Vien, N.B. Colthup, W.G. Fateley, J.G. Grasselli, CHAPTER 13 Cumulated Double Bonds, in: D. Lin-Vien, N.B. Colthup, W.G. Fateley, J.G. Grasselli (Eds.) The Handbook of Infrared and Raman Characteristic Frequencies of Organic Molecules, Academic Press, San Diego, 1991, pp. 213-223.

[50] Y. Yamada, S. Gohda, K. Abe, T. Togo, N. Shimano, T. Sasaki, H. Tanaka, H. Ono, T. Ohba, S. Kubo, T. Ohkubo, S. Sato, Carbon materials with controlled edge structures, Carbon, 122 (2017) 694-701.

[51] N. Iwashita, C.R. Park, H. Fujimoto, M. Shiraishi, M. Inagaki, Specification for a standard procedure of $\mathrm{X}$-ray diffraction measurements on carbon materials, Carbon, 42 (2004) 701-714.

[52] J.J. Venter, M.A. Vannice, Applicability of "drifts" for the characterization of carbon-supported metal catalysts and carbon surfaces, Carbon, 26 (1988) 889902.

[53] J.M. O'Reilly, R.A. Mosher, Functional groups in carbon black by FTIR spectroscopy, Carbon, 21 (1983) 47-51.

[54] C. Moreno-Castilla, M.V. López-Ramón, F. Carrasco-Marín, Changes in surface chemistry of activated carbons by wet oxidation, Carbon, 38 (2000) 19952001.

[55] N. Job, A. Théry, R. Pirard, J. Marien, L. Kocon, J.N. Rouzaud, F. Béquin, J.P. Pirard Carbon aerogels, cryogels and xerogels: Influence of the drying method on the textural properties of porous carbon materials, Carbon, 43 (2005) 2481-2494.

[56] E. Gallegos-Suárez, A.F. Pérez-Cadenas, F.J. Maldonado-Hódar and F. Carrasco-Marín On the micro- and mesoporosity of carbon aerogels and xerogels. The role of the drying conditions during the synthesis processes, Chemical Engineering Journal, 181-182(2012) 851-855

[57] O. Czakkel, K. Marthi, E. Geissler, K. László Influence of drying on the morphology of resorcinol-formaldehyde-based carbon gels Microporous and Mesoporous Materials, 86(2005) 124-133 
Table 1. Lattice parameters of $C X$ and $C A$

\begin{tabular}{llllll}
\hline sample & $\mathbf{d 0 0 2}(\AA)$ & Lc $(\AA)$ & La $(\AA)$ & Nave & $\mathbf{R}$ \\
\hline CXB & 4.0 & 11.6 & 29.1 & 4 & 1.14 \\
CX5 & 4.0 & 11.2 & 28.1 & 4 & 1.28 \\
CX10 & 4.0 & 10.2 & 24.3 & 4 & 1.15 \\
CX15 & 4.0 & 11.4 & 23.3 & 4 & 1.06 \\
\hline CAB & 3.8 & 11.7 & 31.4 & 4 & 1.23 \\
CA5 & 3.8 & 12.4 & 35.3 & 4 & 1.37 \\
CA10 & 3.8 & 12.7 & 34.3 & 4 & 1.41 \\
CA15 & 3.8 & 12.4 & 34.3 & 4 & 1.42 \\
\hline
\end{tabular}


Table 2. Fitting results of the Raman spectral analysis ( ${ }^{*}$ Bands with fixed positions)
D4 $^{*}$
D1
D3
$\mathbf{G}^{*}$
D2

Sample $\quad$ Center FWHM Center FWHM Center FWHM Center FWHM Center FWHM

\begin{tabular}{lllllllllll}
\hline CXB & 1245 & 178 & 1342 & 149 & 1485 & 133 & 1593 & 62 & 1605 & 44 \\
CX 5 & 1245 & 239 & 1342 & 161 & 1493 & 114 & 1593 & 65 & 1598 & 55 \\
CX 10 & 1245 & 246 & 1360 & 168 & 1474 & 143 & 1593 & 76 & 1603 & 59 \\
CX 15 & 1245 & 282 & 1354 & 191 & 1505 & 134 & 1593 & 78 & 1602 & 68 \\
\hline CAB & 1245 & 160 & 1349 & 149 & 1527 & 99 & 1593 & 50 & 1618 & 29 \\
CA 5 & 1245 & 201 & 1348 & 154 & 1520 & 110 & 1593 & 55 & 1618 & 34 \\
CA 10 & 1245 & 192 & 1350 & 152 & 1526 & 118 & 1593 & 50 & 1619 & 35 \\
CA 15 & 1245 & 178 & 1350 & 146 & 1526 & 102 & 1593 & 51 & 1619 & 35 \\
\hline
\end{tabular}


Table 3. Surface characteristics of the carbonaceous materials studied.

\begin{tabular}{llllllll} 
& BET & Vol & mp Area & mp Area & ext Vol & pore & pore \\
& $\left(\mathbf{m}^{2} / \mathbf{g}\right)$ & $\left(\mathbf{c m}^{3} / \mathbf{g}\right)$ & $\left(\mathbf{m}^{2} / \mathbf{g}\right)$ & $\left(\mathbf{m}^{2} / \mathbf{g}\right)$ & $\left(\mathbf{c m}^{3} / \mathbf{g}\right)$ & $\begin{array}{l}\text { diameter } \\
(\mathbf{n m})\end{array}$ \\
\hline CXB & 309 & 0.02 & $34(11 \%)$ & 275 & 0.22 & 15.3 \\
CX5 & 596 & 0.12 & $271(45 \%)$ & 325 & 0.59 & 4.9 \\
CX10 & 685 & 0.13 & $293(42 \%)$ & 392 & 1.35 & 11.6 \\
CX15 & 617 & 0.10 & $222(36 \%)$ & 395 & 1.14 & 10.6 \\
\hline CAB & 522 & 0.10 & $170(33 \%)$ & 352 & 1.00 & 3.7 \\
CA5 & 601 & 0.10 & $216(36 \%)$ & 385 & 0.66 & 2.5 \\
CA10 & 660 & 0.10 & $242(37 \%)$ & 418 & 0.67 & 2.5 \\
CA15 & 615 & 0.11 & $264(43 \%)$ & 351 & 0.62 & 2.7 \\
\hline
\end{tabular}


Table 4. Surface characteristics of the some carbon aerogels and xerogels

\begin{tabular}{|c|c|c|c|c|c|c|c|}
\hline Name & $\begin{array}{l}\text { BET } \\
\left(\mathrm{m}^{2} / \mathrm{g}\right)\end{array}$ & $\begin{array}{l}\text { Vol } \mathrm{mp} \\
\left(\mathrm{cm}^{3} / \mathrm{g}\right)\end{array}$ & $\begin{array}{l}\text { Area } m p \\
\left(m^{2} / g\right)\end{array}$ & $\begin{array}{l}\text { Area ext } \\
\left(\mathrm{m}^{2} / \mathrm{g}\right)\end{array}$ & $\begin{array}{l}\text { Vol pore } \\
\left(\mathrm{cm}^{3} / \mathrm{g}\right)\end{array}$ & $\begin{array}{l}\text { pore } \\
\text { diameter } \\
(\mathrm{nm})\end{array}$ & Ref. \\
\hline \multicolumn{8}{|l|}{ Xerogels } \\
\hline CXB & 309 & 0.02 & $34(11 \%)$ & 275 & 0.22 & 15.3 & $\begin{array}{l}\text { This } \\
\text { work }\end{array}$ \\
\hline Wo & 290 & 0.08 & $101(35 \%)$ & 187 & 0.23 & 3.0 & [11] \\
\hline A0 & 370 & 0.06 & 45 (12\%) & 325 & 0.49 & 5.0 & [11] \\
\hline X1000-115-3 & 215 & $0.09^{\circ}$ & $153(71 \%)$ & -- & $1.9^{\circ}$ & -- & [16] \\
\hline$X 500-115-2$ & 330 & $0.15^{\circ}$ & 255 (77\%) & -- & $0.8^{\circ}$ & -- & [16] \\
\hline X300-115-2 & 330 & $0.15^{\circ}$ & 255 (77\%) & -- & $0.4^{\circ}$ & & [16] \\
\hline$X-50-5.7$ & 460 & $0.21^{\circ}$ & 357 (78\%) & -- & $0.3^{\circ}$ & 2.0 & [55] \\
\hline$X-50-5.7 p$ & $<40$ & $<0.01^{\circ}$ & $<17(42 \%)$ & -- & $<0.1^{\circ}$ & -- & [55] \\
\hline $2-X$ & 550 & $0.22^{\circ}$ & 374 (68\%) & -- & -- & 1.8 & [56] \\
\hline RFxerogel & 110 & 0.04 & 68 (62\%) & 42 & 0.13 & $1.3^{*}$ & [57] \\
\hline xerogel & 891 & 0.34 & $578(65 \%)$ & 313 & 0.44 & $0.54^{*}$ & [57] \\
\hline
\end{tabular}

\section{Aerogels}

$\begin{array}{llllllll}\text { CAB } & 522 & 0,10 & 170(33 \%) & 352 & 1,00 & 3,7 & \begin{array}{l}\text { This } \\ \text { work }\end{array} \\ \text { C0 } & 410 & 0.01 & 123(30 \%) & 287 & 3.07 & 30 & {[11]} \\ \text { A-50-5.7 } & 674 & 0.30^{\circ} & 510(76 \%) & -- & 1.8^{\circ} & 11 & {[55]} \\ \text { A-50-5.7p } & 535 & 0.23 & 390(73 \%) & -- & 0.5 & 8 & {[55]} \\ \text { 2-A } & 704 & 0.28^{\circ} & 477(68 \%) & -- & -- & 6.0 & {[56]}\end{array}$




$\begin{array}{lccccccc}\text { RFaerogel } & 270 & 0.09 & 153(57 \%) & 117 & 0.36 & 1.3^{*} & \text { [57] } \\ \text { aerogel } & 1010 & 0.40 & 680(67 \%) & 330 & 0.79 & 0.7 & \text { [57] }\end{array}$

- Calculated by Dubinin Theory; *pore diameter average 


\section{FIGURE CAPTIONS}

Figure 1. XRD of the prepared $C X(a)$ and $C A$ (b) materials.

Figure 2. Raman spectra of the prepared materials: a) Carbon Xerogels; b) Carbon Aerogels.

Figure 3. First order curve fitting to $\mathrm{CX} 15$ and $\mathrm{CA} 15$.

Figure 4. Representative isotherms at $-196^{\circ} \mathrm{C}$ a) Carbon Xerogels; b) Carbon Aerogels.

Figure 5. Representative SEM micrographs of selected prepared carbons

Figure 6. DRIFT spectra of prepared carbonaceous materials; a) CX series. b) CA series c) Difference spectra showing the influence of the starch addition. 
FIGURE 1
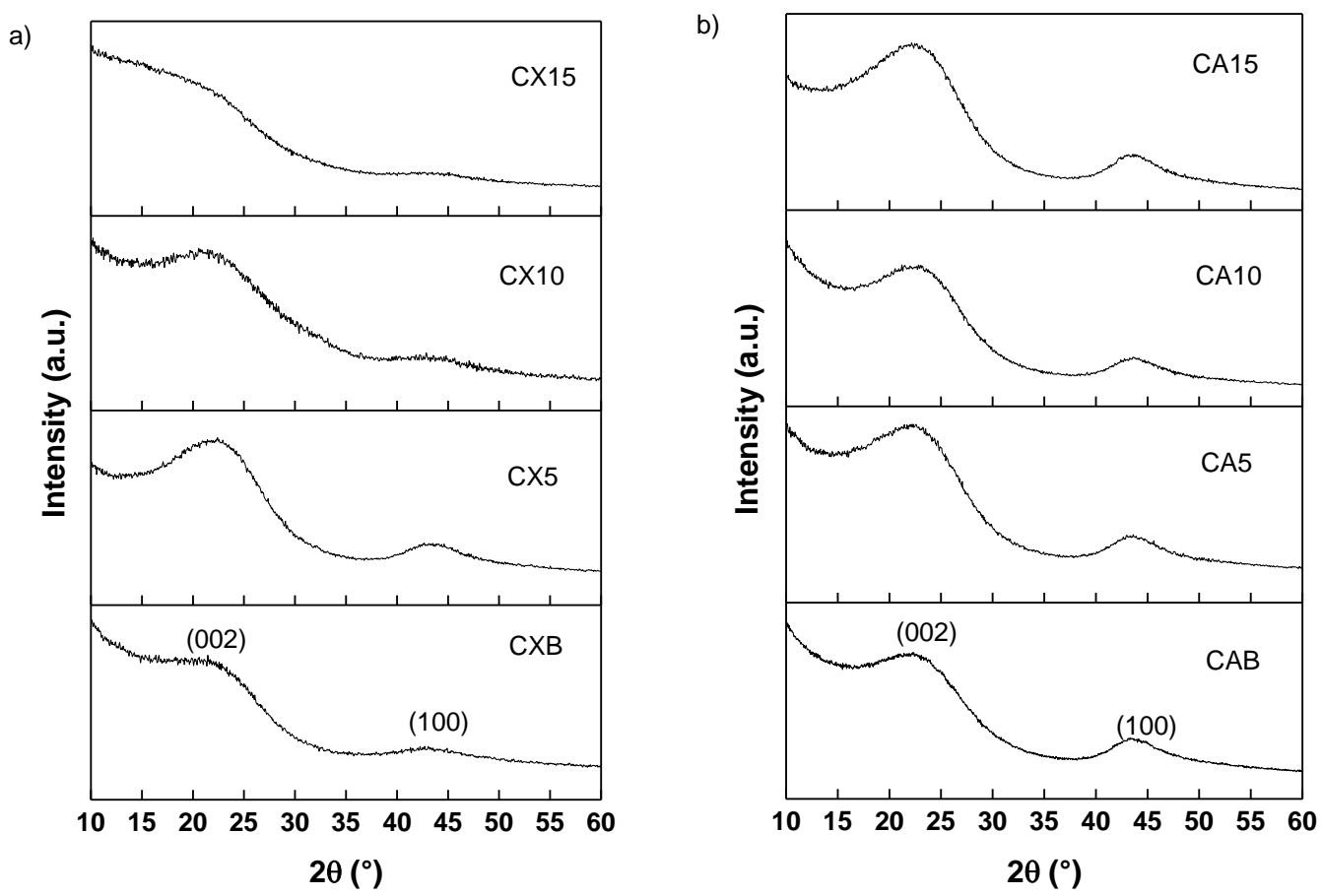
FIGURE 2
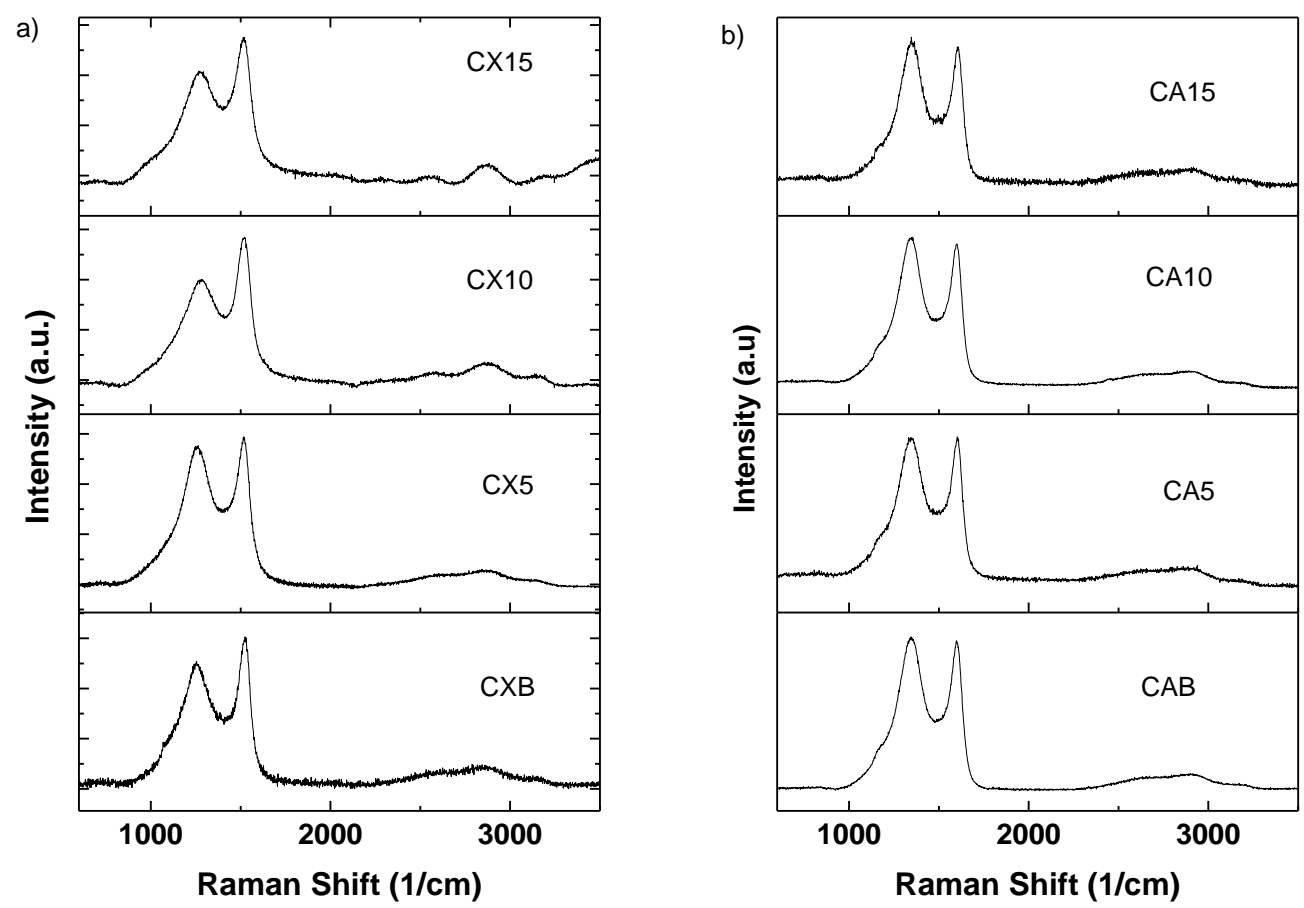
FIGURE 3
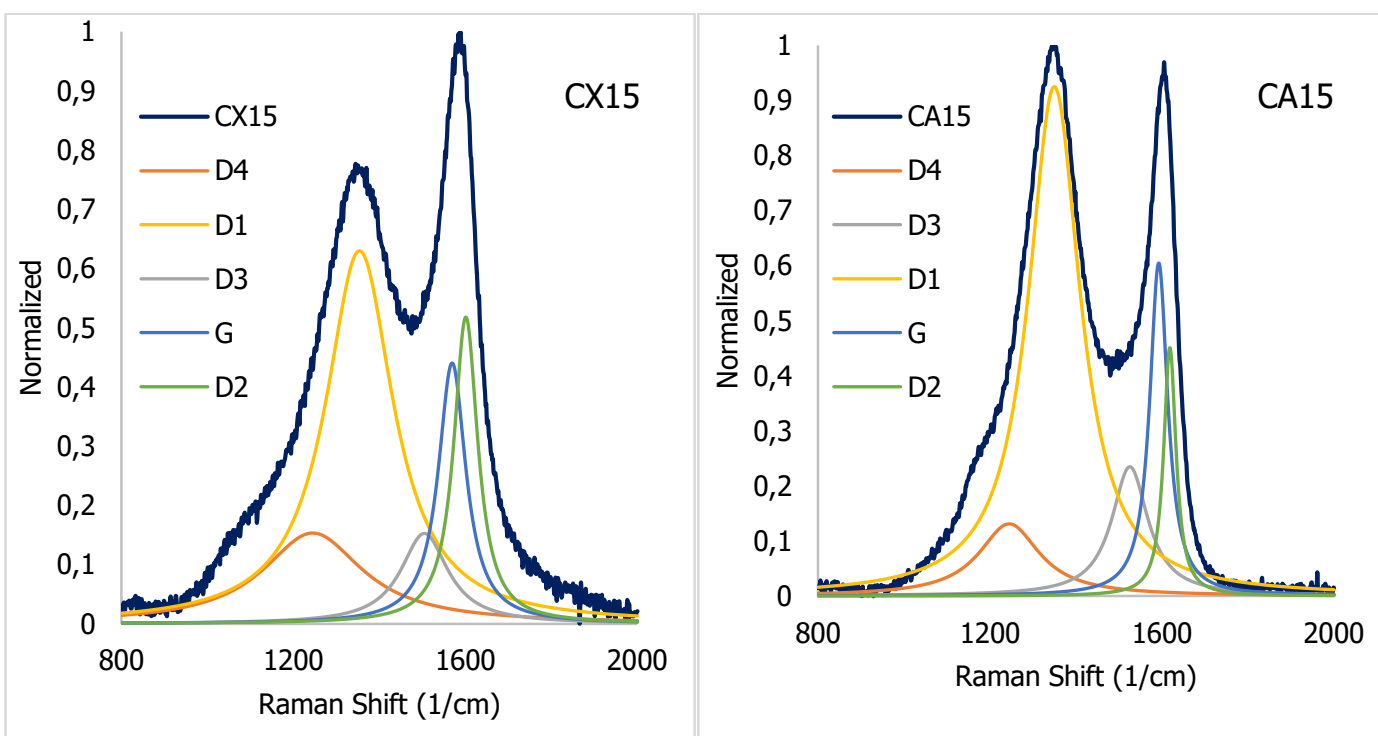
FIGURE 4

a)

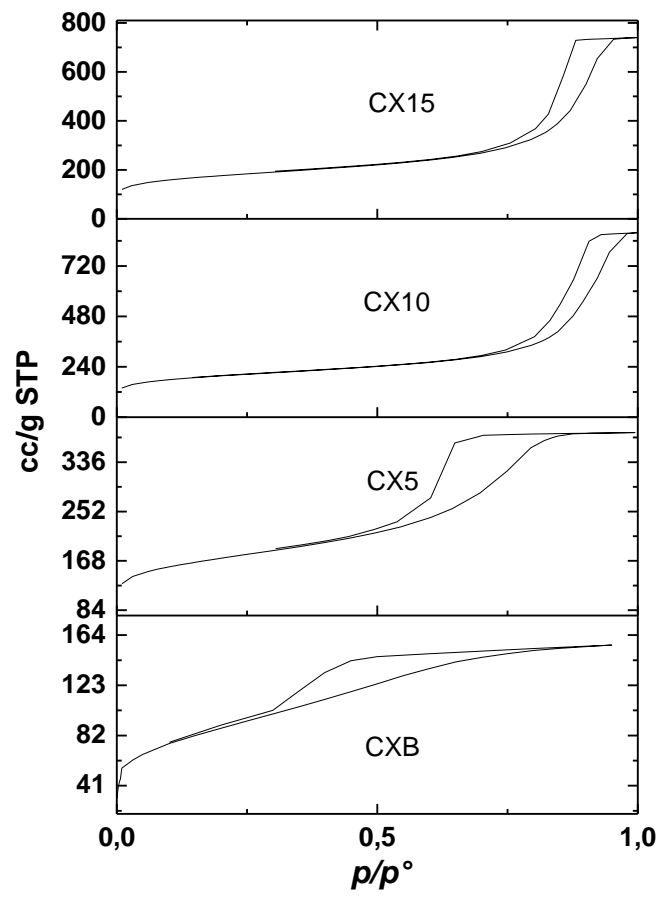

b)

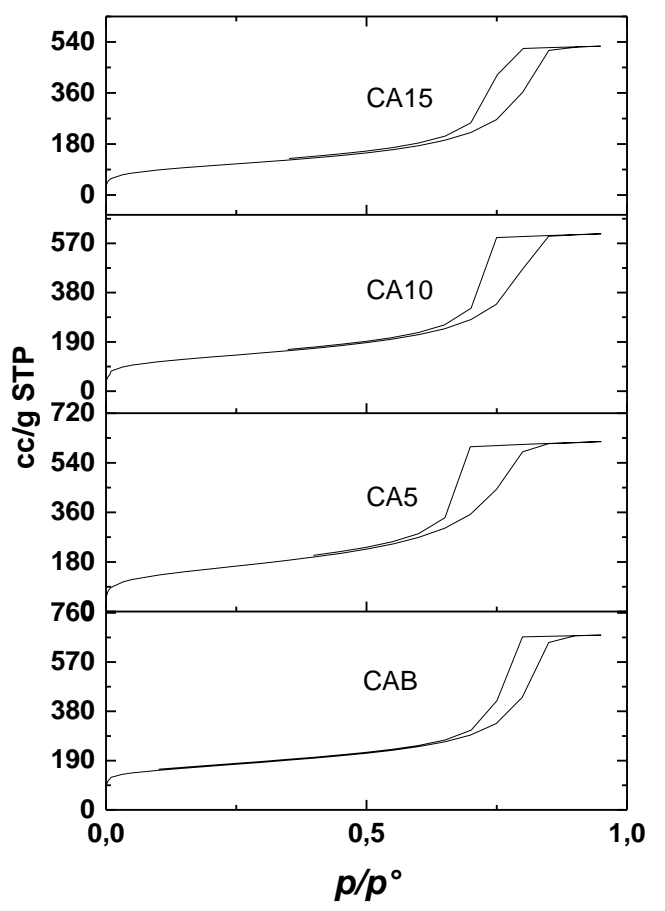


FIGURE 5
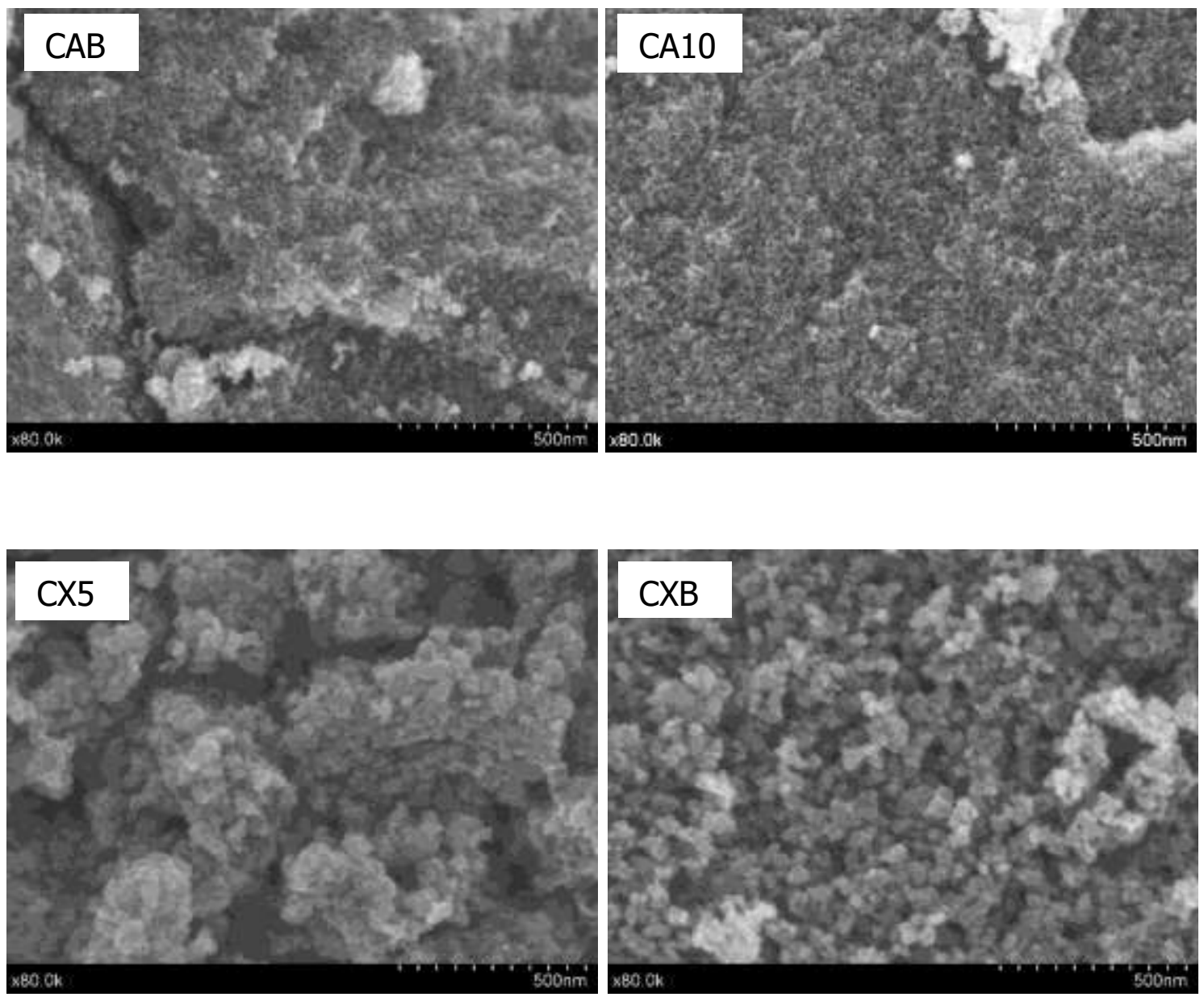
FIGURE 6
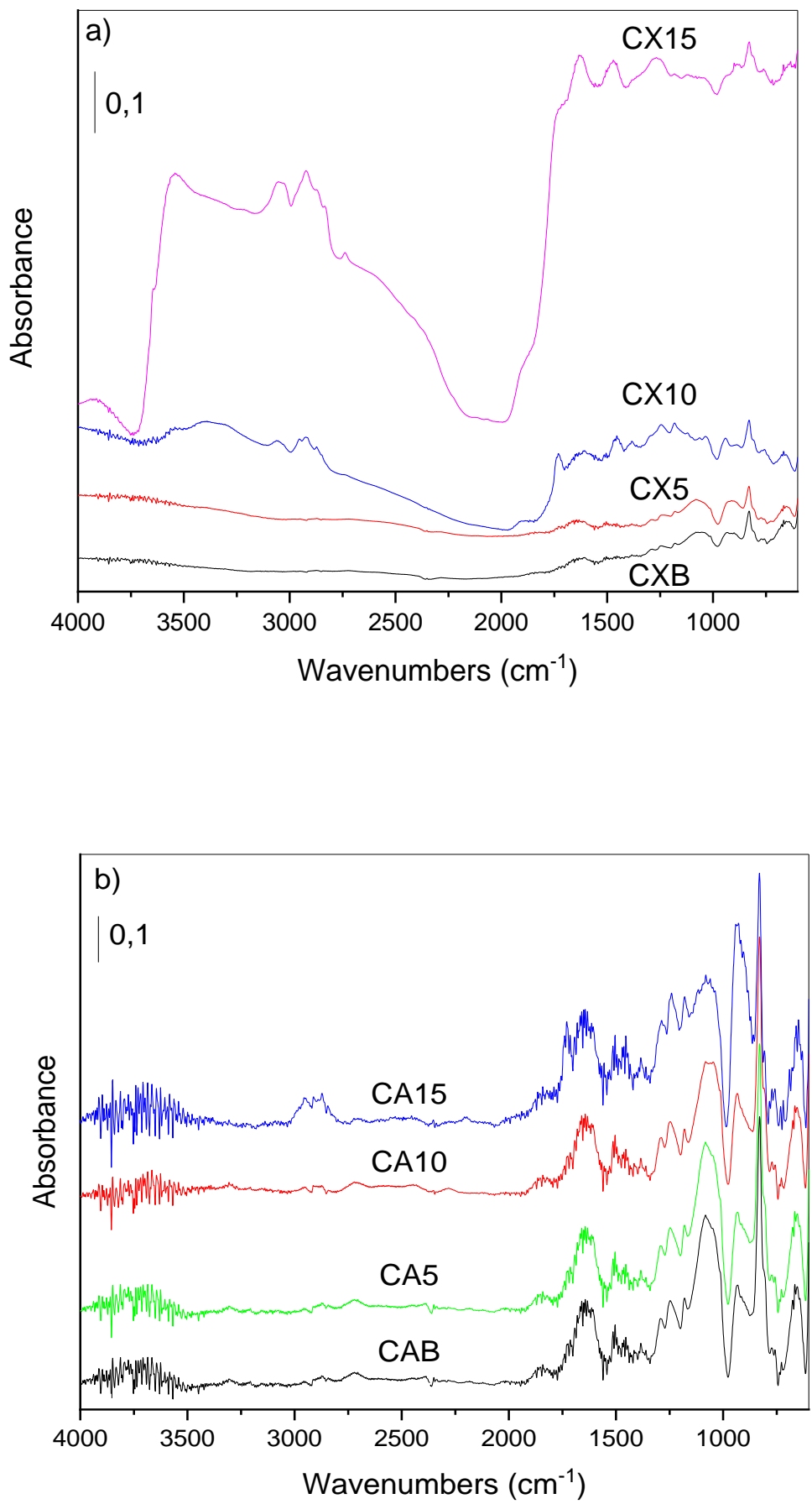


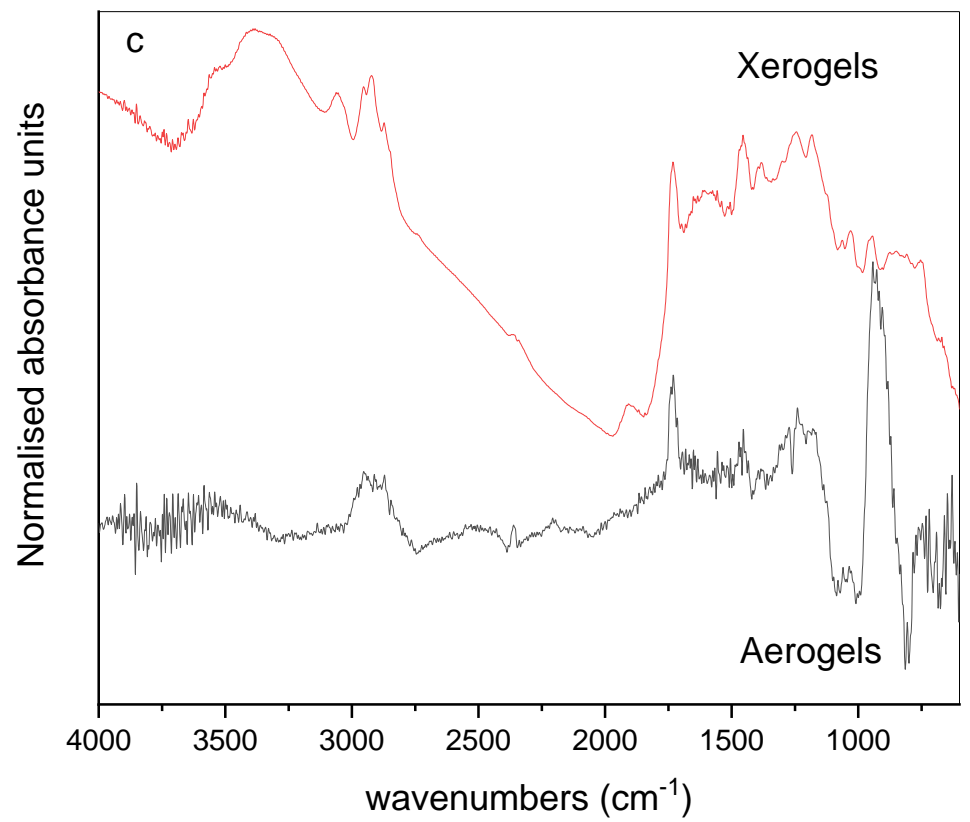

